\title{
De Gustibus
}

\section{Трудности перевода}

\section{Г.А. Герасимов}

\author{
Глобальная сеть по йоду, Бетезда, США
}

\begin{abstract}
Вместе с глобализацией и развитием интернета появились, а затем размножились международные научные журналы открытого доступа (ОД), в которых рукописи можно опубликовать за определенную плату. Нужно сразу оговориться, что основная часть журналов ОД публикуется вполне добропорядочными издательствами, проводящими закрытое рецензирование поступающих к ним рукописей и выпускающими качественный контент. Однако, по некоторым оценкам, не менее четверти журналов ОД являются хищническими, готовыми за деньги публиковать статьи хоть в день их поступления без всякого отбора и рецензирования. Увы, но англоязычные хищнические псевдожурналы можно считать “журналами бедных”, в которых вынуждены публиковаться исследователи из стран с низким подушевым доходом. Так, самыми частыми авторами хищнических научных журналов являются индийцы $(34,7 \%)$, за ними следуют жители других азиатских стран $(25,6 \%)$ и африканцы $(16,4 \%)$. У европейцев и обитателей Северной Америки эти журналы пользуются меньшей популярностью: 8,8 и 9,2\% соответственно. Что неудивительно: все уважающие себя университеты запрещают своим сотрудникам печататься в сомнительных журналах ОД. По мере того как российские исследователи будут ошущать все более возрастающее давление публиковать рукописи в международных журналах на английском языке, вероятность того, что они могут нарваться на хищнический журнал, будет все более возрастать. По мнению автора колонки, нужно постепенно трансформировать известные российские журналы в официально двуязычные, а потом, возможно, принимающие к печати рукописи только на английском языке.
\end{abstract}

Ключевые слова: научные статьи, хищнические журналы, открытый доступ.

\section{Lost in translation Grigory A. Gerasimov}

Iodine Global Network (IGN), Bethesda, MD, USA

\begin{abstract}
Along with globalization and the development of the Internet, new phenomenon have appeared and multiplied: international open access (OA) scientific journals in which manuscripts can be published for a fee. It should be stipulated that the bulk of the OA journals are published by well-respected publishers conducting peer review of the manuscripts and producing high-quality content. However, according to some estimates, at least a quarter of OA journals are "predatory", ready to publish articles for money on the day they are submitted without any selection and review. Unfortunately, predatory journals can be considered "journals of the poor", in which researchers from countries with low per capita income have to publish their manuscripts. The most frequent authors of predatory scientific journals (34.7\%) are Indians, followed by residents of other Asian countries (25.6\%) and Africans (16.4\%). For the Europeans and inhabitants of North America, these magazines are less popular: 8.8 and $9.2 \%$ respectively. What is not surprising: all self-respecting universities prohibit their employees from printing in questionable OA journals. As Russian researchers will feel ever-increasing pressure to publish manuscripts in international journals in English, the likelihood of getting into the claws of a predatory journals will increase. The author believes that gradually it is necessary to transform well-known Russian journals into officially bilingual ones, and then, perhaps, accept manuscripts only in English.
\end{abstract}

Key words: scientific articles, predatory journals, open access.

В Америке популярно выражение: "Что случилось в Лас-Вегасе, остается в Лас-Вегасе"1. Перефразируя его в несколько ином смысле, можно сказать, что почти все научные статьи и книги, опубликованные на русском языке, останутся доступными только русскоязычным читателям. Хотя мне известны энтузиасты, пытавшиеся читать русские

\footnotetext{
1 "What happens in Las Vegas stays in Las Vegas". Смысл этого выражения станет более понятен после просмотра популярной комедии “Мальчишник в Лас-Вегасе".
}

статьи с помощью онлайн-переводчиков, это движение вряд ли когда-нибудь станет массовым.

Недавно в беседе с известным профессоромгастроэнтерологом из Нью-Йорка мой собеседник посетовал, что большое количество статей, опубликованных на русском языке по проблеме дисбактериоза, остаются недоступными западным исследователям. Первой моей мыслью было - может быть, и хорошо, что они недоступны? Быть может, чему-то действительно стоит оставаться “в Лас-Вегасе”? С другой стороны, термин “дисбиоз” (disbiosis) стал 
все более широко использоваться в англоязычной научной литературе [1]. Ведь и само понятие микробиома не было признано мировой наукой до конца 1990-х годов, а сегодня изучение микробиоты является одним из перспективнейших направлений в медицинской науке. Когда Маршалл и Уоррен в 1982 году впервые идентифицировали Helicobacter pylori в желудке и связали эту бактерию с развитием язвы желудка и двенадцатиперстной кишки, это открытие было встречено с большим скептицизмом, так как противоречило всем тогдашним научным канонам. Однако уже в 2005 году оно удостоилось Нобелевской премии в области медицины.

Но статьи по дисбактериозу так и остались без должного осмысления и критики в мелком пуле отечественной науки, и оценить их значимость уже не представляется возможным. “О сколько открытий чудных" может скрываться в пыльных подшивках отечественных научных журналов, доставшихся, по выражению К. Маркса, “грызущей критике мышей”?

Ситуация эта не является уникальной только для российской науки. Глобализация вытолкала ученых из теплых и уютных уголков национальной науки, а вскоре и само это понятие потеряло прежний смысл. Единственным языком науки стал английский, а публикации на других наречиях перестали цениться даже на вес. Адаптироваться к новому средневековью, когда тоже царствовал единый язык науки - латинский, удается не всем.

Другим последствием глобализации последних двух десятилетий стало появление новых научных сверхдержав, таких как Китай и Индия, а также выход на мировую арену большого числа ученых из стран, которые раньше числились в графе развивающихся. Нынче защитить диссертацию и продвинуться в научной карьере без публикаций в “западных" журналах уже невозможно даже в мало кому знакомых африканских и азиатских университетах. При этом количество престижных научных журналов в мире если и увеличилось, то совсем ненамного, а их "пропускная способность" осталась ограниченной. Эта “нерезиновость” доброкачественной научной прессы привела к появлению и быстрому росту числа псевдожурналов для “науки второй свежести”. Забавно, что именно так называлась моя первая колонка De Gustibus, опубликованная в 2010 году [2].

Издание научных журналов является весьма прибыльным бизнесом. Например, издательство Elsevier, издающее около 2,5 тысяч научных журналов, включая знаменитые Lancet и Cell, в 2016 году заработало 2,6 млрд долларов. По оценкам, операционная прибыль традиционных научных издательств составляет около 30\%. Этому весьма способствует их бизнес-модель. Сначала редакции журналов полу- чают от одних ученых бесплатный контент (научные исследования оплачивают университеты и научные институты за счет грантов). Затем они требуют от других ученых бесплатно рецензировать чужие статьи. Если рукописи отвечают определенным требованиям, их публикуют в журналах без выплаты гонораров авторам. А вот подписки на эти же самые журналы продаются издательствами в библиотеки университетов и научных центров за очень большие деньги. Например, годовая подписка на престижный журнал Thyroid c онлайн-доступом и почтовой доставкой новых номеров за пределы США стоит 996 долларов. Чуть ниже цена только онлайнового доступа к контенту - 819 долларов. И это по мировым стандартам далеко не самая высокая подписная цена. Большинству ученых, даже из богатых развитых стран, индивидуальная подписка на научные журналы давно уже стала недоступна.

Сознаюсь, если мне очень нужно прочитать какую-то свежую научную статью в журнале Thyroid или другом подписном журнале, я прошу помощи у коллег, которые имеют свободный онлайн-доступ к университетским библиотекам. В свое оправдание скажу, что к такой услуге я прибегаю довольно редко и вряд ли сильно подрываю прибыли издательского бизнеса.

С развитием интернета в начале двухтысячных годов появилась новая модель научных публикаций - журналы с открытым доступом (ОД). Если традиционные научные журналы обычно требуют передачи издательству авторских прав и получают основную часть своих доходов от подписки и платного доступа к онлайн-контенту, то журналы ОД, напротив, позволяют авторам сохранять авторские права на основании лицензии (часто от Creative Commons) и возможность повторных публикаций результатов исследований в других журналах. В свою очередь эта издательская модель обеспечивает читателей возможностью бесплатного и незамедлительного доступа к опубликованным научным статьям.

Но бесплатным не бывает даже сыр в мышеловке. За возможность публикации своих рукописей журналы ОД собирают с авторов плату (article processing charges - APC). Это означает, что финансовое благополучие журналов целиком зависит от количества опубликованных в них статей. Поскольку журналы ОД не имеют печатных версий, то фактически у них нет ограничений по количеству (и нередко качеству) контента, способного появиться на виртуальных страницах этих уже почти “резиновых” журналов.

Нужно сразу оговориться, что основная часть журналов ОД публикуется вполне добропорядочными издательствами, проводящими закрытое рецен- 
зирование поступающих к ним рукописей и выпускающими качественный контент. Некоторые из журналов ОД стали престижными и знаменитыми, например издающиеся Public Library of Science (PLOS) PLOS One, PLOS Medicine, PLOS Biology и др.

Но наряду с порядочными в интернете во множестве существуют журналы, получившие название хищнических (predatory journals). Этот термин в 2008 году предложил библиотекарь из Университета Колорадо в Денвере (США) Джефри Билл (Jeffrey Beall). Он обратил внимание на все возрастающее число поступающих к нему по электронной почте безграмотных писем от журналов ОД, о которых он не имел ни малейшего представления. Редакции этих журналов готовы были публиковать любой контент фактически без всякого рецензирования, их владельцы часто предпочитали оставаться инкогнито, а механизмы оплаты выглядели весьма подозрительно.

Авторы статьи в журнале ВМС Medicine (солидном журнале, также относящемся к категории ОД), опубликованной в 2015 году [3], оценили объем годовых доходов хищнических журналов примерно в 74 млн долларов. Пока это относительно немного. Например, доходы журналов ОД с хорошей репутацией составляли 244 млн долларов, а традиционных журналов с подписной моделью бизнеса - 10,5 млрд долларов. По мнению Д. Билла, не менее 25\% журналов ОД следует относить к категории хищнических, а доля этих журналов на рынке издательской продукции будет постоянно возрастать. Ведь для открытия хищнических журналов практически не нужны начальные инвестиции, расходы на их деятельность минимальны: достаточно только открыть страницу в интернете и придумать звонкое название.

При выборе названия владельцы хищнических журналов часто имитируют имена уже хорошо известных журналов с высокой репутацией. Например, называют новый журнал Journal of Preventive Medicine, что очень созвучно названию издающегося c 1972 года журнала Preventive Medicine от Elsevier.

А поднакопив деньжат, издатели хищнических журналов стали применять новые трюки. Вот, например, журнал Experimental and Clinical Cardiology в течение 17 лет издавало добропорядочное канадское научное издательство, он распространялся по подписке и имел высокий импакт-фактор. Но несколько лет тому назад этот журнал купил неизвестный инвестор. Он преобразовал его в журнал ОД и установил цену за публикацию рукописи в 1200 долларов США. Это примерно среднерыночная цена для добропорядочных журналов ОД. Но одновременно произошла и другая метаморфоза: если в 2013 году этот журнал опубликовал в бумажной версии 63 научные статьи, то в 2014 году количество выпущенных в интернет статей превысило тысячу. Конечно, какое-то число статей в новой версии журнала вполне отвечало высоким требованиям, которые этот журнал предъявлял ранее. Тем хуже для авторов качественных статей, которые по ошибке разместили свои рукописи в хищническом журнале и, сами того не зная, себя скомпрометировали.

Среди хищнических издательств есть настоящие гиганты, например Omics International, выпускающий (по информации его владельца) 1000 журналов ОД, публикующий 50 тыс. статей в год и проводящий около 3 тыс. научных конференций. Да, да, да! Фейковыми стали не только журналы, но и научные конференции! Деятельность этого издательства недавно стала предметом расследований журнала Bloomberg Businessweek [4]. Основал это издательство в 2008 году индийский паренек по имели Гедела, который забросил работу над докторской диссертацией ради прибыльного бизнеса (потом он научную степень все же получил). Вся начальная инвестиция на покупку интернет-домена для будущего издательства составила 200 рупий (меньше 4 долларов).

Следует заметить, что Индия является безусловным лидером в издании хищнических журналов. Chen и Bjork в 2015 году опубликовали интересное исследование [5] хищнических журналов, список которых долгое время вел упомянутый выше американский библиотекарь Д. Билл. Авторами было показано, что родиной $27 \%$ хищнических журналов является Индия, 11,6\% издавались в других азиатских странах (чаще всего в Пакистане), а местожительство $26,8 \%$ журналов авторам установить вовсе не удалось. Меньшее число плотоядных журналов $(17,5 \%)$ прописалось в Северной Америке (США и Канаде), a 8,8\% нашли пристанище в Европе (преимущественно восточной ее части).

Индийцы являются также и самыми частыми авторами хищнических научных журналов (34,7\%), за ними следуют жители других азиатских стран $(25,6 \%)$ и африканцы $(16,4 \%)$. У европейцев и обитателей Северной Америки эти журналы пользуются меньшей популярностью: 8,8 и 9,2\% соответственно. Что неудивительно: все уважающие себя университеты в цивилизованных, скажем так, частях света под угрозой увольнения запрещают своим сотрудникам печататься в журналах из черного списка, составленного Д. Биллом.

Впрочем, сам Д. Билл в январе 2017 года закрыл свой блог, в котором он 6 лет публиковал свой черный список (число хищнических журналов в нем за этот период выросло с 18 до 1155). Как сам он утверждает, сделать это ему пришлось из-за давления руководства университета, поскольку владелец издательства Omics господин Гедела (почти все журналы 
которого оказались в этом списке) стал грозиться иском в миллиард долларов за якобы порушенную деловую репутацию [4]. Иска он так и не подал, но осадок остался. Университет, впрочем, с такой версией событий не согласен.

Почти 90 лет тому назад пролетарский писатель Максим Горький назвал джаз “музыкой толстых", что пришлось по вкусу советской пропаганде. По моему мнению, и без всякой идеологической подоплеки хищнические журналы можно считать “журналами бедных”, в которых вынуждены публиковаться исследователи из стран с низким подушевым доходом. Заблуждаться не следует: в подавляющем большинстве ученые, направляющие рукописи в журналы с сомнительной репутацией, прекрасно осведомлены о том, с кем имеют дело. Но царствующий в современной науке принцип “публиковать или погибнуть” (“publish or perish”) не оставляет им достойной альтернативы.

Опубликовать статью в престижном “нерезиновом” журнале, издающемся в Европе или США, новичку из научной провинции практически невозможно. Но если карьера висит на волоске, то статья в англоязычном журнале со звонким названием оставляет определенные надежды на будущее.

Исследователи подсчитали процентное соотношение между количеством статей в хищнических и респектабельных научных журналах, индексируемых в Web of Science, учеными из четырех стран, чаще всего публикующимися в хищнических журналах. Хотя по числу таких авторов США вошли в призовую четверку, это соотношение было невелико всего 6\%. Но в Иране этот показатель составлял уже $70 \%$, в Индии - 277\%, а в Нигерии - целых $1580 \%$ [5]. То есть в Индии на одну качественную статью приходилось почти 3 статьи в хищническом журнале, а Нигерии - почти 16 !

Более того, ученые из бедных стран чаще были вынуждены платить за публикацию в журналах ОД из личных средств. Европейские и американские университеты обычно покрывают своим сотрудникам расходы в объеме 1000-1500 долларов на публикацию статей в добропорядочных журналах ОД (их список заранее определяется специальной комиссией). Только $10 \%$ авторов из богатых стран (с ВВП на душу населения свыше 25 тыс. долларов) платили за публикацию в журнале ОД из собственных средств, тогда как $39 \%$ авторов из стран с более низкими доходами вынуждены были платить за статьи из собственного кармана [5]. Нужно отметить, что это наблюдение касалось журналов ОД с хорошей репутацией, индексируемых в Directory of Open

\footnotetext{
${ }^{2}$ http://gorkiy.lit-info.ru/gorkiy/articles/article-80.htm
}

Access Journals (DOAJ), треть из которых были отмечены в Journal Citation Report (JCR). Это отчасти объясняет, почему ученые из бедных стран обращаются к хищническим журналам, плата за публикацию рукописи в которых минимальна: в среднем 178 долларов [3].

Трудно сказать, какое число российских исследователей направляют свои рукописи в англоязычные хищнические журналы. Думаю, не так много. Видимо, подобно ученым из стран Южной Америки (их доля в авторстве статей в англоязычных хищнических журналах была всего 2,3\%), россияне попрежнему предпочитают публиковать статьи на родном языке.

Однако, судя по количеству назойливых писем от неизвестных журналов и издательств, которые я стал регулярно находить в “мусорном ящике” своей электронной почты на русскоязычном домене mail. ru, отечественные исследователи также стали объектом внимания индустрии хищнических журналов (как отечественных, так и преимущественно индийских), которые предлагают широкий спектр услуг за сравнительно небольшие деньги.

Смело утверждаю, что уважающий себя журнал ОД никогда не рассылает по электронной почте письма, рекламирующие свои услуги. Эта деятельность мало чем отличается от пресловутых “нигерийских писем”, в которых мошенники просят у получателя помощи в многомиллионных денежных операциях, обещая солидные проценты с сумм. Если получатель согласится участвовать, у него постепенно выманиваются все более крупные суммы денег якобы на оформление сделок, уплату сборов, взятки чиновникам и т.п. ${ }^{3}$

L. Shamseer и соавт. [3] сформулировали несколько признаков, предположительно указывающих на хищнический характер журнала. Это их “всеядность": в сферу интереса журнала входят как биомедицинские исследования, так и все иное, за что автор готов заплатить. Часто интернет-страница англоязычного псевдожурнала содержит грамматические ошибки, а изображения выглядят нечеткими или искаженными (скорее всего, их просто откуда-то украли). При описании цитируемости журнала может переоцениваться значение индекса Copernicus Value, который рядом специалистов считается почти жульническим. Плохо, если на веб-странице журнала отсутствует описание процесса отбора, рецензирования и подготовки рукописи к печати, а также процедуры отзыва рукописи. Журнал, претендующий на открытый доступ, не должен пытаться присвоить себе авторские права на опубликованные статьи или

\footnotetext{
${ }^{3}$ https://ru.wikipedia.org/wiki/Нигерийские_письма
} 
обходить эту тему молчанием. Неправильно, если рукописи статей запрашиваются по электронной почте, а не загружаются на веб-странице журнала, а контактный адрес электронной почты зарегистрирован на общедоступных доменах, таких как @gmail. com или @yahoo.com. Хищнические журналы обычно гарантируют быструю (в течение нескольких дней) публикацию рукописи за сравнительно небольшую плату (часто меньше 150 долларов). В добропорядочном журнале ОД плата в 7-10 раз выше.

По мере того как российские исследователи будут ощущать все более возрастающее давление (от собственного начальства, Академии наук, ВАК или иных инстанций) публиковать рукописи в международных журналах на английском языке, вероятность нарваться на хищнический журнал будет все более возрастать. Как этого избежать?

Как говорил, готовясь к карнавальной ночи, товарищ Огурцов: “Бабу-Ягу со стороны брать не будем. Воспитаем в своем коллективе”. По примеру наших коллег из бывших соцстран Центральной Европы, которые первыми ощутили на себе это давление еще четверть века тому назад, надо трансформировать известные российские журналы сначала в официально двуязычные, а потом, возможно, принимающие к печати рукописи только на английском языке. А как иначе можно добиться того, чтобы отечественные журналы входили в Web of Science, Scopus и другие базы данных респектабельных научных журналов?

Естественно, в этом процессе придется столкнуться с “трудностями перевода": рукописи должны быть написаны на достаточно грамотном англий- ском языке (не обязательно совершенном, это придет со временем), а рецензентам и редакторам научных журналов поначалу будет непросто перестроить, умно выражаясь, modus operandi.

Однако лучше это сделать раньше, чем потом с печалью вспоминать слова известного с детства стихотворения К.И. Чуковского ${ }^{4}$.

\section{Список литературы [References]}

1. Carding S, Verbeke K, Vipond DT, et al. Dysbiosis of the gut microbiota in disease. Microb Ecol Health Dis. 2015;26:26191. doi: 10.3402/mehd.v26.26191.

2. Герасимов Г.А. О науке второй свежести. // Клиническая и экспериментальная тиреоидология. - 2010. - Т. 6. - №2. C. 11-12. [Gerasimov GA. O nauke vtoroy svezhesti. Clinical and experimental thyroidology. 2010;6(2):11-12. (In Russ.)] doi: 10.14341/ket20106211-12.

3. Shamseer L, Moher D, Maduekwe O, et al. Potential predatory and legitimate biomedical journals: can you tell the difference? A cross-sectional comparison. BMC Med. 2017;15(1):28. doi: 10.1186/s12916-017-0785-9.

4. Bloomberg.com [Internet]. Depres E, Chen C. Medical journals have a fake news problem [updated 2017 Aug 29; cited 2017 Sep 4]. Available from: https://www.bloomberg.com/news/features/ 2017 08-29/medical-journals-have-a-fake-news-problem

5. Shen C, Bjork BC. 'Predatory' open access: a longitudinal study of article volumes and market characteristics. BMC Med. 2015; 13:230. doi: 10.1186/s12916-015-0469-2.

\footnotetext{
4 “Маленькие дети! Ни за что на свете не ходите в Африку, в Африку гулять! В Африке акулы, в Африке гориллы, в Африке большие, злые крокодилы”.
}

\section{Информация об авторе [Authors info]}

Герасимов Григорий Анатольевич, д.м.н., профессор, региональный координатор Глобальной сети по йоду по странам Восточной Европы и Центральной Азии [Grigory A. Gerasimov, MD, PhD, Professor]; e-mail: gerasimovg@inbox.ru; eLibrary Author ID: 296623.

\section{Как цитировать}

Герасимов Г.А. Трудности перевода // Клиническая и экспериментальная тиреоидология. - 2017. - Т. 13. №3. - C. 6-10. doi: 10.14341/ket201736-10

\section{To cite this article}

Gerasimov G.A. Lost in translation. Clinical and experimental thyroidology. 2017;13(3):6-10.

doi: $10.14341 / \operatorname{ket} 201736-10$

Рукопись получена: 27.11.2017. Одобрена: 28.11.2017. О Опубликована online: 10.12.2017.

Received: 27.11.2017Ａccepted: 28.11.2017. Published online: 10.12.2017. 